\title{
Enhancing power loss by optimal coordinated extensive CS operation during off-peak load at the distribution system
}

\author{
$S N$ Syed Nasir ${ }^{1 *}, J J \operatorname{Jamian}^{1}, R$ Ayop ${ }^{1}$ and $M W$ Mustafa $^{1}$ \\ ${ }^{1}$ School of Electrical Engineering, Faculty of Engineering, Universiti Teknologi Malaysia (UTM), Malaysia
}

\begin{abstract}
Minimise dependency of energy from depleted non-renewable had pushed the usage of electric vehicle (EV). However, the presence of charging station (CS) may cause another impact such as higher power loss, especially involving uncoordinated CS. The impact becomes vital when the numbers of CS to charge the EV increased dramatically. From research, CS at residential usually operated during off-peak load. Furthermore, the variation of the charging pattern that difficult to perceive had added severe condition. Thus, the exploration of the mitigation method is necessary to avoid the stress at the existing distribution network. This paper suggests a coordinated method based on the power loss forecast throughout the charging time. The method will prioritise the buses based on power loss impact on the network, which later to determine the suitable numbers of CS operation. The approach considers customer satisfaction to charge the EV at a specific duration fully. Thus, to present the effectiveness of the approach, the analysis conducted using a suitable distribution system with residential block. The results show a positive outcome in enhancing distribution power loss without interrupt customer satisfaction. The method is suitable to deal with many CS that operates simultaneously during off-peak load.
\end{abstract}

\section{Introduction}

From numerous visions by every country throughout the globe, EV expected to become significant for future modern transportation. Although EV offers a short driving range and the stress of significantly delayed time to recharge compared to the conventional vehicle, EV also provides the long-term solution to environment issue [1]. From the environmental view, EV capable of decreasing needs on the fossil fuel transport division, with reducing carbon dioxide and heat emission [2]. Furthermore, from the forecast, EV global usage expected to grow from more than one million in 2017 to eleven million by 2025 and stay raised more than thirty million by 2030, with about one-third of the global transportation moving to electric by 2040 [2-3]. However, the spread of EV usage may create another problem, especially during charging of EV battery [4-6]. The impact becomes critical while involving large-scale penetration of EVs, which can harm the power quality, reliability, and stability of the grid, especially without adequate mitigation [3-8].

There are two common approaches for EV charging coordination which are decentralised and centralised [7-13]. Decentralised approaches usually do not require robust communication infrastructure for data exchange between customer and aggregator compared to the centralised approach. For example, the centralised approached require data from customers such as battery SOC, plug-in and plug-out time to forecast the load demand. Other than that, centralise approach manage to achieve comprehensive performance due to global coordination compared to decentralised. Although the centralised involve higher infrastructure investment, the outcome is valuable for a long term vision. Various researchers propose the centralised method in coordinating EV based on scenarios and objective function. For instance, many types of research strived at enhancing the power quality of the grid by executing various approaches and strategies, such as adopting demand-side management and installing additional reactive devices at an optimal location in the network [5, 6]. Next, research at [7] shows that by coordinating the EV charging may reduce the cost by shifting the EV charging loads and also able to accommodate more CS operation in the network. Other than that, the better coordination between generation and EV charging also produce optimal power flow in the distribution system [8]. Also, research at [9] validated dynamic charging based on a two-stage hierarchical decision-making process which able to manage thousands of CS in realtime. Jian L et al. [11] proposed a valley filling strategy scheme to coordinate CS operation. The scheme introduces capacity margin index and priority index which used to select the target time state on which the grid has sufficient excess power for EV charging and to ascertain the charging priority of EVs, respectively.

Therefore, this research proposes the proper method for coordinating CS operation in centralise environment with the assistance of meta-heuristic techniques. The research concentrate on lowering total power losses with high customer satisfaction during off- 
peak load. The proposed method will look at the best time to charge the EV battery depending on distribution system condition and battery sizing. Since there are two objective function involve, multi-objective which is weight summation approached will be adopted. Additionally, the profile of load and CS will apply useful data from earlier research. Hence, in the means of optimising the charging strategies, precise parameters such as the variation of loads and battery state of charge (SOC) are considered. This paper arranged into five sections. The first section explains the significance of charging strategies and popular research focus while Section 2 defines in detail the significant parameters modelling such as distribution system network, EV battery, CS characteristic, load profile and objective function. Next, section 3 pointed on the methodology in determining the optimal charging sequence based on the bus priority with the assistance of metaheuristic method. In section 4 , focus on outcomes and the discussion on the results while the research conclusion in Section 5.

\section{Problem Formulation}

These sections will concentrate on modelling the distribution system by considering CS locations. Next, to concentration on the relevant formula to determine battery SOC based on open-circuit voltage theory and its efficiency. Moreover, the typical load profile and CS pattern design also presented. Then, the formula of the multi-objective functions, which are power loss and customer satisfaction, will be detailed out.

\subsection{Distribution System Modelling}

The distribution system demonstrated based on typical load variation and CS operation. In the direction of viewing the real-world application, IEEE $23 \mathrm{kV} 10$-bus radial distribution system applied for this research with added two $415 \mathrm{~V}$ low voltage residential block that has 19 buses each as per represented in Figure 1. Employing the research emphasis on bulk CS operation, every residential block buses will be placed one unit CS which designed to charge one EV only as per illustrated in Figure 2. Then, the line data for residential block is presented at Table 1 .

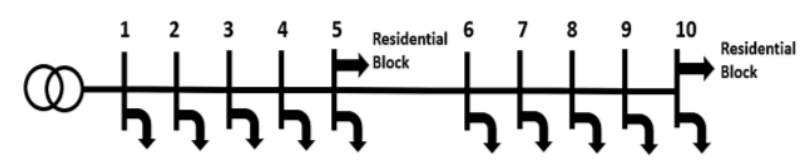

Fig. 1. IEEE 10-bus radial distribution system with two residential blocks.

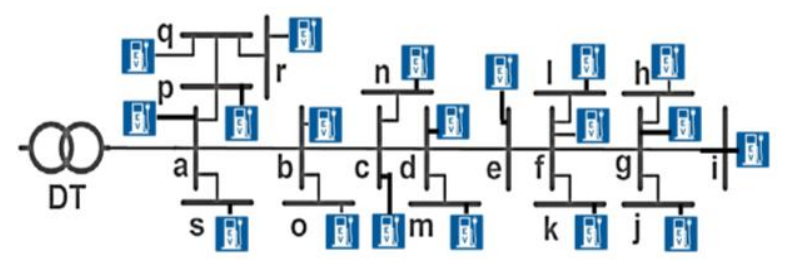

Fig. 2. $415 \mathrm{~V}$ 19-bus residential block with CS.
Table 1. Line data for residential block network

\begin{tabular}{|c|c|c|c|c|}
\hline 㪯 & 咅 & 壱 & $\simeq \frac{\hat{\Xi}}{\hat{\theta}}$ & $\times \widehat{\frac{\hat{E}}{\mathrm{e}}}$ \\
\hline 10 & 10 & $\mathrm{a}$ & 0.0000 & 0.0654 \\
\hline 11 & $\mathrm{a}$ & $\mathrm{b}$ & 0.0415 & 0.0145 \\
\hline 12 & $\mathrm{a}$ & $\mathrm{p}$ & 0.0424 & 0.0189 \\
\hline 13 & $\mathrm{a}$ & $\mathrm{s}$ & 0.0444 & 0.0198 \\
\hline 14 & $\mathrm{~b}$ & $\mathrm{c}$ & 0.0369 & 0.0165 \\
\hline 15 & $\mathrm{~b}$ & o & 0.0520 & 0.0232 \\
\hline 16 & c & $\mathrm{d}$ & 0.0524 & 0.0234 \\
\hline 17 & $\mathrm{c}$ & $\mathrm{n}$ & 0.0005 & 0.0002 \\
\hline 18 & $\mathrm{~d}$ & $\mathrm{e}$ & 0.2002 & 0.0199 \\
\hline 19 & $\mathrm{~d}$ & $\mathrm{~m}$ & 1.7340 & 0.1729 \\
\hline 20 & $\mathrm{e}$ & $\mathrm{f}$ & 0.2607 & 0.0260 \\
\hline 21 & $\mathrm{f}$ & $\mathrm{g}$ & 1.3605 & 0.1357 \\
\hline 22 & $\mathrm{f}$ & $\mathrm{k}$ & 0.1400 & 0.0140 \\
\hline 23 & $\mathrm{f}$ & 1 & 0.7763 & 0.0774 \\
\hline 24 & g & $\mathrm{h}$ & 0.5977 & 0.0596 \\
\hline 25 & $\mathrm{~g}$ & $\mathrm{i}$ & 0.1423 & 0.0496 \\
\hline 26 & $\mathrm{~g}$ & $\mathrm{j}$ & 0.0837 & 0.0292 \\
\hline 27 & $p$ & $q$ & 0.3123 & 0.0311 \\
\hline 28 & q & $\mathrm{r}$ & 0.0163 & 0.0062 \\
\hline
\end{tabular}

\subsection{Battery and CS Modelling}

Typically, EV comprises a battery to store energy that will be useful for driving for a certain distance depending on battery size. Plenty of battery sizes designed based on customer distance specification and necessity. Besides, CS being design based on different output depends on customer request such as low charging current if the customer has sufficient time (4-7 hours) to charge fully and slightly higher current if the customer needs faster charging (2-3 hours). However, relating to this research, the output current of CS has fixed value by seeing that CS cannot deviate the output current. There are two types of battery size used as per Table 2, where both sizes require different time duration to charge fully. For instance, types 1 and types 2 battery that has sizes of $50 \mathrm{kWh}$ and $80 \mathrm{kWh}$ require 4.5 hours and 7 hours to charge, respectively fully. However, the time duration calculated based on initial battery SOC of $15 \%$ to meet $95 \%$ SOC. Moreover, charging requires reactive power since the $\mathrm{CS}$ itself is designed based on the existence of the electronic circuit. Additionally, the battery efficiency used is $92 \%$ considering practical EV battery application.

Table 2. EV battery data specification.

\begin{tabular}{|l|c|c|}
\hline \multirow{2}{*}{\multicolumn{1}{|c|}{ Description }} & \multicolumn{2}{c|}{ CS Level 2 (9.6kW) } \\
\cline { 2 - 3 } & Type 1 & Type 2 \\
\hline EV Battery (kWh) & 50 & 80 \\
\hline SOC Initial (\%) & 15 & 15 \\
\hline SOC final (\%) & 90 & 90 \\
\hline Current (A) & 40 & 40 \\
\hline Real Power (P) & 8928 & 8928 \\
\hline Reactive Power (Q) & 1785.6 & 1785.6 \\
\hline Duration (h) & 4.5 & 7 \\
\hline
\end{tabular}

Lithium batteries represent a regular battery model employed for the analysis. The SOC plug-in and plug- 
out battery value depend on customer inquiry while the current produced by CS to the EV battery is the same by considering output current at all CSs are fixed. General equation to identify SOC at the current state is using battery open-circuit voltage [14] as shown in equation (1).

$$
\begin{aligned}
& V_{O C V}=3.135-0.685\left(-\ln (S O C)^{0.478}-1.342 . S O C+\right. \\
& \left.1.734 e^{0.4(S O C-1)}\right) \\
& \operatorname{SOC}\left(\Delta \mathrm{t}_{\mathrm{k}+1}, \mathrm{i}\right)=\operatorname{SOC}\left(\Delta \mathrm{t}_{\mathrm{k}+1}\right)+\left(\frac{\Delta \mathrm{t}}{\mathrm{Q}_{\mathrm{i}}} \mathrm{I}\left(\Delta \mathrm{t}_{\mathrm{k}}, \mathrm{i}\right) \cdot\right.
\end{aligned}
$$

100)

\subsection{Load Profile}

There are normal load, and EV load involves in this research. Both loads are consuming on usual daily customer variation pattern. Other than that, CS operation will follow EV customer behaviour to charge while load consumption from CS depends on battery sizing as well as component efficiency. Figure 3 design based on time which every increment number represent 15 minutes different with the first time started at $8 \mathrm{pm}$. Next, Figure 3 also shows the load profile for the normal load without $\mathrm{EV}$ and with EV for daily consumption. Besides that, the power loss difference calculated based on power loss during system without EV and with EV also recorded in Figure 3. The CS operation modelled to operate off-peak load between 8 pm until 7am where most of the CSbased on level 2 types operated.

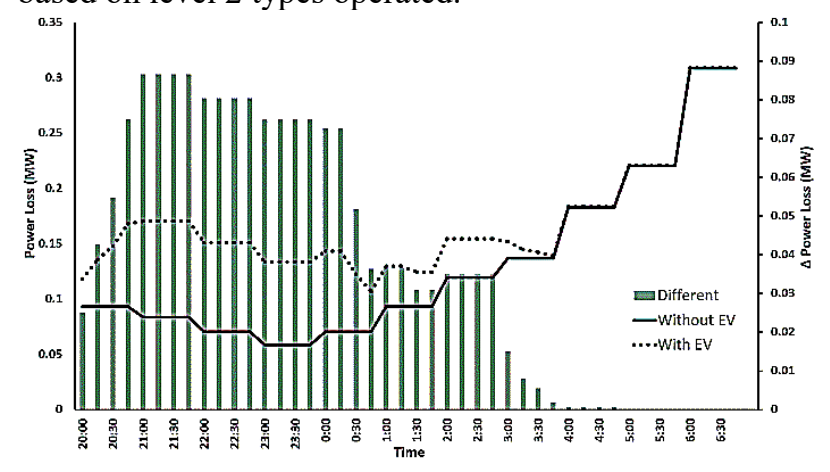

Fig. 3. Power loss with EV, without EV and different between 20:00 to 07:00.

\subsection{Objective Function}

The main parameter involve in this research are power loss and customer satisfaction. The calculation of apparent power loss is based on sum of apparent power losses that produce from all lines for as per equation (2) while total power loss equation can be compute using equation (3) with consider time duration of $k$.

$$
\begin{aligned}
& \bar{S}_{\text {loss }-k}=\sum_{l=1}^{n} \bar{V}_{i, l} \cdot \bar{I}_{i j, l}^{*}+\bar{V}_{j, l} \cdot \bar{I}_{j i, l}^{*} \\
& P_{\text {loss }}=\sum_{i=1}^{k} \operatorname{real}\left(\bar{S}_{\text {loss }-k}\right)
\end{aligned}
$$

where:

$\bar{S}_{\text {loss }}$ - Apparent power losses

$P_{\text {loss }}$ - Real power losses

$\bar{V}_{i, l}$ - Local voltage at $l^{\text {th }}$ line
$\bar{V}_{j, l} \quad$ - Remote voltage at $l^{\text {th }}$ line

$\bar{I}_{i j, l}$ - Current flow from local to remote $l^{\text {th }}$ line

$\bar{I}_{j i, l}$ - Current flow from remote to local at $l^{\text {th }}$ line

$n$ - Total number of lines

Next, formula to calculate customer satisfaction is based on ability of CS to fully charge all battery within $8 \mathrm{pm}$ until 7am. Equation (4) shows the fundamental formula to calculate customer satisfaction ( Cust $_{\text {sat }}$ ) where $m$ represent number of battery that need to be charged. Moreover, $S O C_{\text {init }}$ and $S O C_{\text {req }}$ are represent battery SOC at initial before charging start and SOC request by customer to end the charging, respectively. Then, $S O C_{\text {final }}$ represent final value of SOC at $7 \mathrm{am}$. The foremost rationale for choosing 7 am as a cut-off for measuring customer satisfaction is due to most of the customer starts to drive $\mathrm{EV}$ in the daylight to travel to the office.

$$
\text { Cust }_{\text {Sat }}=1-\frac{\sum_{i=1}^{m} S O C_{\text {final }}-S O C_{\text {init }}-\left(100-S O C_{\text {final }}\right)}{\sum_{i=1}^{m} S O C_{\text {req }}}
$$

Considering there are two parameters which are power loss and customer satisfaction, multi-objective function with weight summation approach will be adopted to get a better solution. For the first fitness, ratio parameter of power loss with the current value as per equation (5) while customer satisfaction using equation (6) set as second fitness. Both finesses used to form summation fitness equation (7). Lastly, weight parameter $k_{1}$ and $k_{2}$ will set to 0.5 for this research to show significant of both parameters.

$$
\begin{aligned}
& \text { fit }_{1}=\frac{\sum_{i=1}^{k} P_{\text {loss }-i}}{\sum_{i=1}^{k} P_{\text {loss-i-existing }}} \\
& \text { fit }_{2}=\text { Cust }_{\text {Sat }} \\
& \text { Fitness }=k_{1} f i t_{1}+k_{2} \text { fit }_{2}
\end{aligned}
$$

\section{Methodology}

The process for coordinating CS operation presented in this section. The metaheuristic method, which is Particle Swarm Optimization (PSO) used as assistance to find optimal coordination. The PSO method prefers due to the ability to finding the optimum solution for complex power system problem [15-16]. The flowchart in Figure 4 describes the PSO procedure in finding the optimal coordination of CS operation. The particle $x_{i}$ represents the number of CS that optimally operate at each time slot (between 1 to 44). The chosen depend on two parameters which are power loss and customer satisfaction that represent fitness value. Next, iteration is set at 100 to make sure the result is converged with the best solution. The detailed flowchart in finding the fitness shown in Figure 5. Fitness calculation based on the sum of $k$ time slot. The reason to simulate 44-time slots is to make sure customer satisfaction is to stay higher.

Moreover, bus priority is based on power loss that contributes from individual $\mathrm{EV}$ to the system for the 
entire 44-time slots as per Figure 6. Based on Figure 6, the influence for each EV to total power loss is different for every time slots. Thus, this will assist the metaheuristic to determine the most suitable combination of CS operation that offers less total power loss to the system.

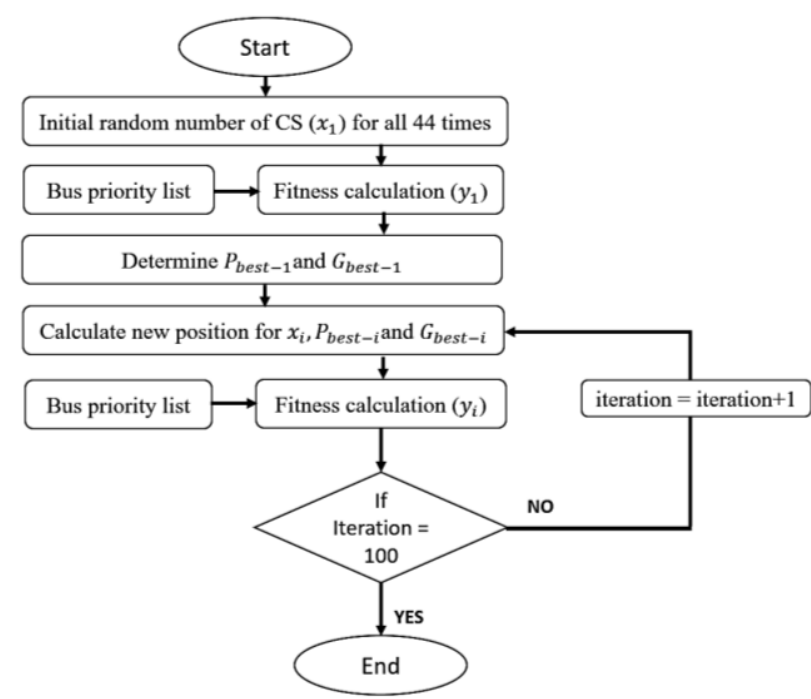

Fig. 4. Flowchart procedure for PSO

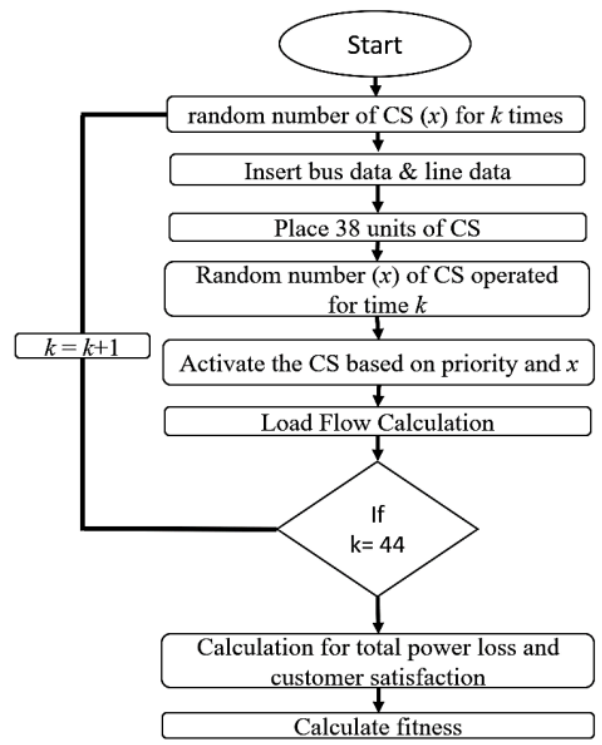

Fig. 5. Flowchart in finding the fitness

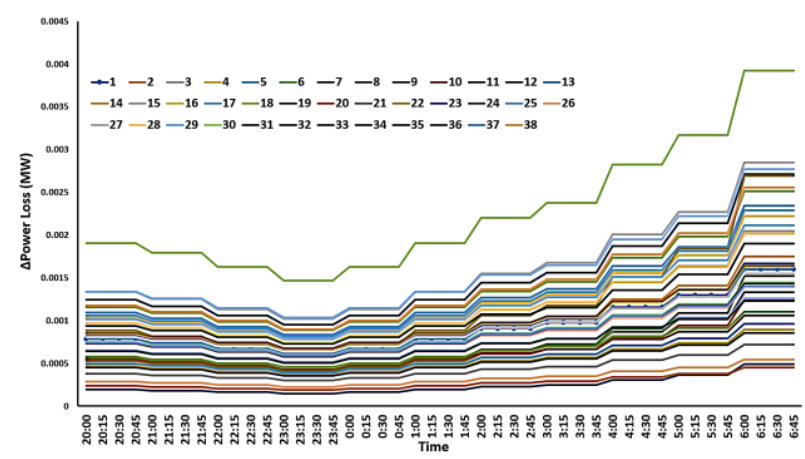

Fig. 6. EV charging impact between 8pm to $7 \mathrm{am}$.

\section{Result and Discussion}

The case in this research design is based on the situation where 38 units of CS operated during off-peak in low voltage $415 \mathrm{~V}$ buses with two battery sizes that having different time for a full charge. The analysis based on eleven hours which represent 44-time slots (between 8 pm until $7 \mathrm{am}$ ), where 15 minutes is equivalent to each time slot. The battery $S O C_{\text {init }}$ for all EV is set at $15 \%$ while $S O C_{r e q}$ is set at $90 \%$. Customer satisfaction measures the ability of CS to charge all the EV battery within $8 \mathrm{pm}$ until $7 \mathrm{am}$. Based on the existing distribution system without $\mathrm{EV}$ and with $\mathrm{EV}$, total power losses recorded for eleven hours is $1.437641 \mathrm{MW}$ and $1.864708 \mathrm{MW}$, respectively. Since all battery manages to full charge before 7 am, makes customer satisfaction become $100 \%$.

Next, after adopting the proposed method for coordinating the CS operation, the result is promising which the power loss registered at $1.798322 \mathrm{MW}$, which declines of $0.066387 \mathrm{MW}$. Based on coordinated EV, customer satisfaction shows $100 \%$, which all batteries are achieving $90 \%$ SOC. From the simulation based on PSO converge value, the CS operation being distributed almost all the time slots as per Figure 7. From the analysis, the starting of CS operation simultaneously by all customer cause higher power loss to the network; however, with the proper coordination of CS operation, less power loss can be achieved.

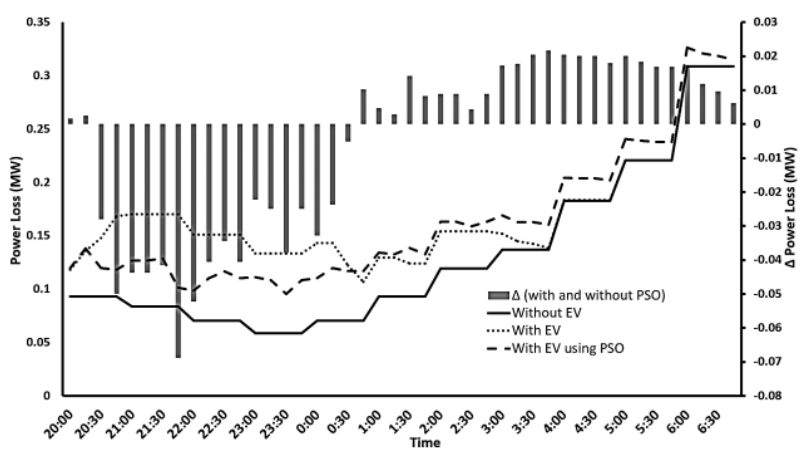

Fig. 7. Power loss without EV, with EV, with EV using PSO and different between 20:00 to 07:00,

From Figure 7, the system is less stress during first five hours with the controlled numbers of CS operation in the system, the placement of CS operation after 1 am had cause increment of power losses compared to the existing system, but as overall power losses for eleven hours, the power loss is enhanced. The impact of propose method is significant since consider for daily operation which will offer less stress to network. Furthermore, customer satisfaction still shows a comparable result which reveals the suggested method will not impose problem to customers. 


\section{Conclusion}

A proposed methodology for the coordinated CS operation during off-peak load in the distribution system has been presented in this paper. The metaheuristic technique used with a focus on scheduling numbers of CS that operate optimally for every 15 minutes. Other than that, the priority bus also introduces to show a better time for every bus to operate based on low power loss. From the final arrangements, the enhancement 3.5\% of power loss without interrupt customer satisfaction after optimal simulation with PSO assistance shows the proposed method is worth.

Acknowledgments. The researchers would like to express their appreciation to the Universiti Teknologi Malaysia (UTM) for supporting this work through UTMER Grant (17J76).

\section{References}

1. J. Neubauer, E. Wood, The impact of range anxiety and home, workplace, and public charging infrastructure on simulated battery electric vehicle lifetime utility, J. Power Sources, 257, 12 (2014)

2. P. Cazzola, M. Gorner, R. Schuitmaker, E. Maroney, Global EV outlook 2017: Two Million and Counting International Energy Agency France (2017)

3. S. Falahati, SA. Taher, M. Shahidehpour, A new smart charging method for EVs for frequency control of smart grid, International Journal of Electrical Power \& Energy Systems, 83, 458 (2016)

4. S. Deb, K. Tammi, K. Kalita, P. Mahanta, Impact of electric vehicle charging station load on distribution network, Energies, 11, 178 (2018)

5. S. Bahrami, VWS. Wong, J. Huang, An online learning algorithm for demand response in smart grid, IEEE Trans. Smart Grid, 9, 4712 (2017)

6. AS. Masoum, S. Deilami, PS. Moses, MAS. Masoum, Smart Load Management of Plug-In Electric Vehicles in Distribution and Residential Networks with Charging Stations for Peak Shaving and Loss Minimization Considering Voltage Regulation, IET Proc. Gener. Transm. Distrib, 5, 877 (2011)

7. H Chen, Z Guo, Y Xin, Y Zhao, Coordination of PEV Charging across Multiple Stations in
Distribution Networks Using Aggregate PEV Charging Load Model, In Proceedings of the 2017 International Smart Cities Conference (ISC2), (2017)

8. S Bruno, S Lamonaca, M La Scala, Load control through smart metering on distribution networks, In Proceedings of the IEEE Bucharest Power-Tech, (2019)

9. Z. Yia, D. Scoffielda, J. Smarta, A. Meintzb, M. Junb, M. Mohanpurkara, A. Medama, A highly efficient control framework for centralised residential charging coordination of large electric vehicle populations, Electrical Power and Energy Systems, 117 (2020)

10. S. Deilami, SM. Muyeen, An insight into practical solutions for electric vehicle charging in smart grid, Energies, 13(7),1545 (2020)

11. L. Jian, Y. Zheng, Z. Shao, High efficient valleyfilling strategy for centralised coordinated charging of large-scale electric vehicles, Appl Energy, 186, 46 (2017)

12. S. Sun, Q. Yang, J. Ma, AJ. Ferré, W. Yan, Hierarchical planning of PEV charging facilities and DGs under transportation-power network couplings, Energy, 150, 356 (2020)

13. N. Rezaei, A. Khazali, M. Mazidi, A. Ahmadi, Economic energy and reserve management of renewable-based microgrids in the presence of electric vehicle aggregators: A robust optimisation approach, Energy, 117629 (2020)

14. C. Zhang, J. Jiang, L. Zhang, S. Liu, L. Wang, PC. Loh, A Generalized SOC-OCV Model for LithiumIon Batteries and the SOC Estimation for LNMCO Battery, Energies, 9(11), 900 (2016)

15. K. Ye, P. Li, H. Li, Optimization of hybrid energy storage system control strategy for pure electric

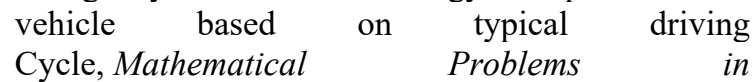
Engineering, (2020).

16. X. Lin, G. Zhang, S. Wei, Y. Yin, Energy consumption estimation model for dual-motor electric vehicles based on multiple linear regression, International Journal of Green Energy, 1-13 (2020) 